American Journal of Applied Sciences 6 (5): 1010-1014, 2009

ISSN 1546-9239

(C) 2009 Science Publications

\title{
Effects of ZnO on Dielectric Properties and Electrical Conductivity of Ternary Zinc Magnesium Phosphate Glasses
}

\author{
S.F. Khor, Z.A. Talib, H.A.A. Sidek, W.M. Daud and B.H. Ng \\ Department of Physics, Faculty of Science, University Putra Malaysia, \\ 43400, Serdang, Selangor, Malaysia
}

\begin{abstract}
Five different compositions of the ternary system $(\mathrm{ZnO})_{\mathrm{x}}(\mathrm{MgO})_{30}\left(\mathrm{P}_{2} \mathrm{O}_{5}\right)_{70-\mathrm{x}}$ containing 8,10 , 13, 15 and $18 \mathrm{moL} \%$ of $\mathrm{ZnO}$ were prepared by the melt quenching technique. The complex permittivity studies were presented in the frequency range of $0.01 \mathrm{~Hz}$ to $1 \mathrm{MHz}$ and over the temperature range of 303-573 K. The empirical data were analyzed by means of the curve-fitting technique based on Havriliak-Negami model. A small broad dipolar relaxation peak was well described at frequencies between $10^{3}$ and $10^{6} \mathrm{~Hz}$ within the range of temperatures studied, while at low frequency the spectrum was dominated by dc conduction which was evidence by $1 / \omega$ slope in the loss factor versus frequency plot. With increasing $\mathrm{ZnO}$ concentration, the dielectric $\left(\varepsilon^{\prime}\right)$ and dielectric strength $(\Delta \varepsilon)$ both show an increasing trend while the dc conduction behaved in the opposite direction. The excessive zinc ions occupying interstitial position rather than substitutional position among the glass network and increases of the compactness of the glass structure have been suggested to be the reason behind the declining values of the dc conduction.
\end{abstract}

Key words: Dielectric properties, conductivity, harviliak-negami

\section{INTRODUCTION}

Phosphate glasses are both scientifically and technologically important materials because of their structural versatility to accept several cation and/or anion exchanges. These features allow the reengineering of glass formulation, which leads to advances in their physical properties ${ }^{[1]}$ and for commercial exploitation purposes. Thus, an investigation on the relationship between the composition and properties of these materials was seen to be important. The study on dielectric properties such as dielectric constant, dielectric loss and ac conductivity of phosphate glasses over a wide range of frequency and temperature is expected not only to reveal comprehensive knowledge about the nature and origin of the loss occurring in these materials as well as conduction mechanism but also provide information on the structural aspect of the glasses ${ }^{[2,3]}$.

$\mathrm{BeO}-\mathrm{P}_{2} \mathrm{O}_{5}, \mathrm{ZnO}-\mathrm{P}_{2} \mathrm{O}_{5}$ and $\mathrm{MgO}-\mathrm{P}_{2} \mathrm{O}_{5}$ glasses are classified as anomalous glasses. They exhibited unusual discontinuity in composition/property (e.g., refractive index and molar volume) behaviour at the metaphosphate composition ${ }^{[4]}$. Moreover, an admixture of $\mathrm{MgO}$ and $\mathrm{ZnO}$ into phosphate composition has not yet been reported before and it is of interest to investigate on its physical, refractive and dielectric properties. Thus, the present study reports the dielectric properties and conductivity performed on $(\mathrm{ZnO})_{\mathrm{x}}(\mathrm{MgO})_{30}\left(\mathrm{P}_{2} \mathrm{O}_{5}\right)_{70-\mathrm{x}}$ glasses over a wide range of compositions, temperatures and frequencies.

Data from dielectric spectroscopy can be analyzed using four different complex formalisms: impedance, $\mathrm{Z}^{*}$, admittance, $\mathrm{Y}^{*}$, permittivity, $\varepsilon^{*}$ and electric modulus, $\mathrm{M}^{*}$. These formalisms are interrelated, i.e.:

$$
Z^{*}=\frac{1}{Y^{*}}=\frac{1}{j \omega \varepsilon * C_{0}}=\frac{M *}{j \omega C_{0}}
$$

Where:

$\omega=$ The angular frequency

$\mathrm{C}_{\circ}=$ The empty cell capacitance

The dielectric properties of usual interest are the real $\left(\varepsilon^{\prime}\right)$ and imaginary $\left(\varepsilon^{\prime \prime}\right)$ components of the complex permittivity $\varepsilon^{*}(\omega)=\varepsilon^{\prime}(\omega)$-i $\varepsilon^{\prime \prime}(\omega)$. The permittivity of a material reflects the molecular relaxation and transport processes of the material which depends on many parameters such as temperature, time and pressure ${ }^{[5]}$.

Corresponding Author: Z.A. Talib, Department of Physics, Faculty of Science, University Putra Malaysia, 43400, Serdang, Selangor Tel: + (603)89466646 Fax: + (603)89454454 


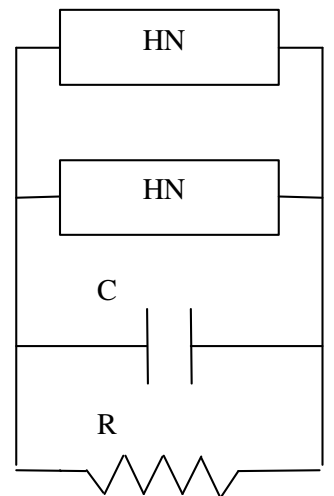

Fig. 1: Equivalent circuit used to model the dielectric response of $(\mathrm{ZnO})_{\mathrm{x}}(\mathrm{MgO})_{30}\left(\mathrm{P}_{2} \mathrm{O}_{5}\right)_{70-\mathrm{x}}$ glass

The empirical data of this study was sufficiently fitted by using Havriliak-Negami (HN) dielectric relaxation function, superimposed by a conductivity term as shown below:

$$
\begin{aligned}
& \varepsilon^{*}=\varepsilon^{\prime}-i \varepsilon^{\prime \prime} \\
& =\sum_{\mathrm{k}=1}^{\mathrm{m}}\left\{\frac{\Delta \varepsilon_{\mathrm{k}}}{\left[1+\left(i \omega \tau_{\mathrm{k}}\right)^{\alpha_{k}}\right]^{\beta_{k}}}+\varepsilon_{\omega_{\mathrm{k}}}\right\}-\mathrm{i}\left(\frac{\sigma_{\circ}}{\varepsilon_{\mathrm{o}} \omega}\right)^{\mathrm{n}}
\end{aligned}
$$

Where:

$$
\sigma_{\circ}=\text { The dc conductivity }
$$

$\Delta \varepsilon_{\mathrm{k}}=$ The dielectric strength of the kth relaxation

$\tau_{\mathrm{k}}=$ The relaxation time of the kth component

$\alpha=$ The width parameter

$\beta=$ The asymmetry parameter

$\varepsilon_{\infty_{k}}=$ The infinite permittivity of the kth relaxation and $\mathrm{n}$ is an exponential factor

The complex permittivity of the studied glasses has been modeled by assuming the circuit in Fig. 1. The equivalent circuit consists of two $\mathrm{HN}$ terms, a capacitance and resistance which are in parallel combination. The capacitance, $\mathrm{C}$ and resistance, $\mathrm{R}$, described the high frequency permittivity and dc conduction, respectively. The first $\mathrm{HN}$-function represents the small broad loss peak in the high frequency range of dielectric loss factor plot, while the second $\mathrm{HN}$-function represents electrode polarization.

\section{MATERIALS AND METHODS}

The starting chemical powders, phosphorus (V) oxide (99.99\%), magnesium oxide (98\%) and zinc oxide $(99.7 \%)$ were weighed and mixed together in an alumina crucible in appropriate quantities to constitute a 15-20 g batch. The crucible was covered and heated in an electric furnace for about $1 \mathrm{~h}$ at a temperature of $400^{\circ} \mathrm{C}$. The crucible was then transferred to another electric furnace and kept at $1200^{\circ} \mathrm{C}$ for $2 \mathrm{~h}$. The melt was stirred occasionally every $20 \mathrm{~min}$ to ensure homogeneity and proper mixing. Each melt was cast by pouring it into a preheated stainless steel cylindrical two-split mould to form glass rods of about $20 \mathrm{~mm}$ long and $10 \mathrm{~mm}$ in diameter. After casting, each glass was immediately transferred to an annealing furnace and held at a temperature of $400^{\circ} \mathrm{C}$ for $1 \mathrm{~h}$ and slowly cooled to room temperature. The samples were prepared by cutting the glasses into disc-form and both faces of the samples were polished using silica carbide in order to get a glass with smooth and parallel faces. Pure aluminum $(99.999 \% \mathrm{Al})$ was evaporated onto both sides of the samples as electrode by using Vacuum Coating (Edwards Auto 306). The samples were stored in a desiccator until dielectric relaxation measurements were performed by using High-Resolution Dielectric Analyzer (Novocontrol).

\section{RESULTS AND DISCUSSION}

In a dielectric study, the real part of permittivity $\left(\varepsilon^{\prime}\right)$ represents the polarizability of the material while the imaginary part $\left(\varepsilon^{\prime \prime}\right)$ represents the energy loss due to polarization and ionic conduction ${ }^{[6]}$. Dielectric materials have four distinguishable polarization mechanisms, namely electronic, atomic, orientation and interfacial or space charge polarization ${ }^{[7]}$. Figure 2 shows the dielectric response of $(\mathrm{ZnO})_{\mathrm{x}}(\mathrm{MgO})_{30}\left(\mathrm{P}_{2} \mathrm{O}_{5}\right)_{70-\mathrm{x}}$ for $\mathrm{x}=15$ which is $\mathrm{a}$ representative of the dielectric characteristic behaviour for all glasses studied. As clearly observed in Fig. 2a, a step-like decrease of the dielectric constant occurs at below $10^{2} \mathrm{~Hz}$ and shifts towards higher frequencies with increasing temperature. This step-like distribution is attributed to electrode polarization effects. However, its corresponding loss peak cannot be seen in the $\varepsilon^{\prime \prime}$ spectra on account of the dominant influence of conduction losses ${ }^{[8]}$. For the present series of glasses, no obvious dispersions were detected at higher frequency range from the $\varepsilon^{\prime}$ spectra. However, from the curve-fitting analysis, a dispersion is revealed which corresponds to the first $\mathrm{HN}$-function in Fig. 1. At a low frequency, the $\varepsilon^{\prime \prime}$ spectrum is dominated by $\mathrm{dc}$ conduction which was indicated by the $1 / \omega$ slope of the loss factor plot shown in Fig. 2b. $\varepsilon^{\prime \prime}$ is found to increase with increasing temperature and a small broad dielectric loss peak has been observed for all measured temperature ranges. The position of these loss peaks which have onsets of $10^{4} \mathrm{~Hz}$ gradually shifted toward higher frequencies with increasing temperature. 

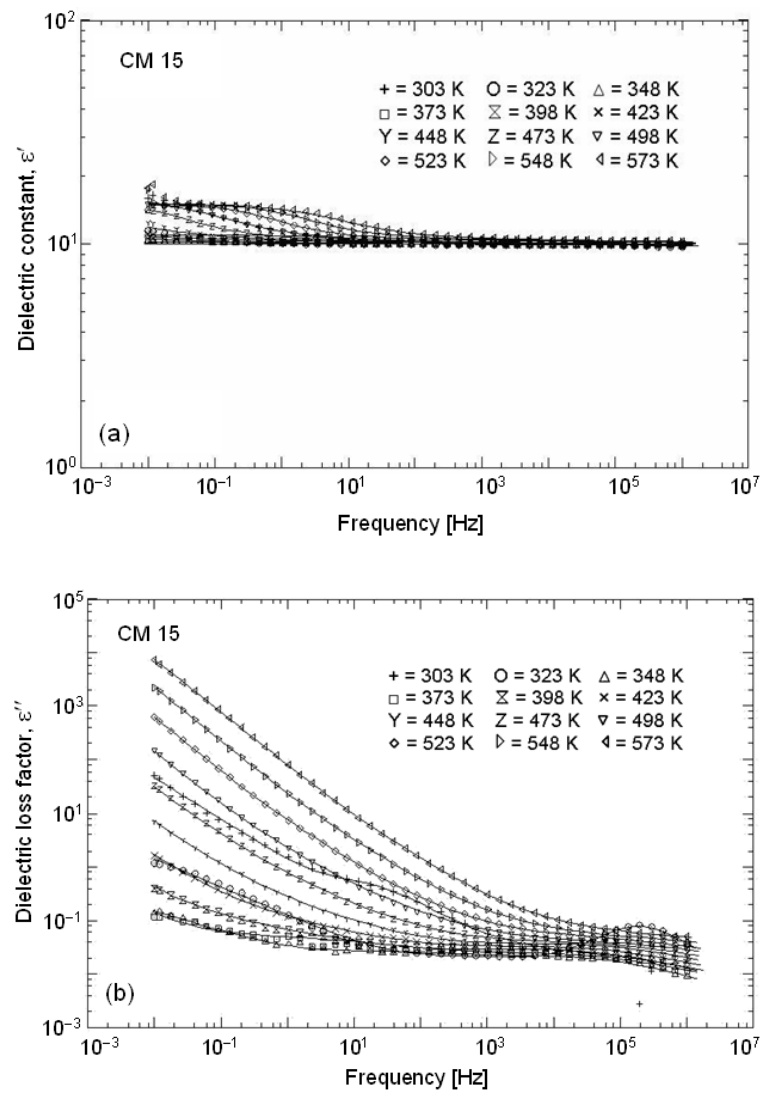

Fig. 2: Dielectric permittivity (a) and dielectric loss factor (b) in the frequency domain for $(\mathrm{ZnO})_{\mathrm{x}}(\mathrm{MgO})_{30}\left(\mathrm{P}_{2} \mathrm{O}_{5}\right)_{70-\mathrm{x}}$ glasses at $\mathrm{x}=15$. Solid line indicates fitting by the HavriliakNegami equation superimposed with a conductivity term by using Winfit

Figure 3 shows the variation of dc conductivity $\left(\sigma_{\mathrm{dc}}\right)$ with temperature and $\mathrm{ZnO}$ mole $\%$ concentration. The dc conduction decreases as $\mathrm{ZnO}$ content is raised up to $\mathrm{x}=18$ and increases for $\mathrm{x}=20$. This increase may be attributed to the conversion of the glass ultraphosphate which compose of $\mathrm{Q}^{3}$ and $\mathrm{Q}^{2}$ unit to metaphosphate composition which only consists $\mathrm{Q}^{2}$ unit. $(\mathrm{ZnO})_{\mathrm{x}}(\mathrm{MgO})_{30}\left(\mathrm{P}_{2} \mathrm{O}_{5}\right)_{70-\mathrm{x}}$ glasses have a complex composition and are an admixture of network formers, intermediates and modifiers which were being differentiated and classified according to the value of electronegativity and bond strength as pointed out by Stanworth $^{[9]}$ and Sun ${ }^{[10]}$, respectively. In the present system, a fixed amount of the modifier $\mathrm{MgO}$ will form an almost same amount of Non-Bridging Oxygen (NBO) sites in all the glasses and $\mathrm{Mg}^{2+}$ ions are incorporated into the network interstices ${ }^{[11]}$.

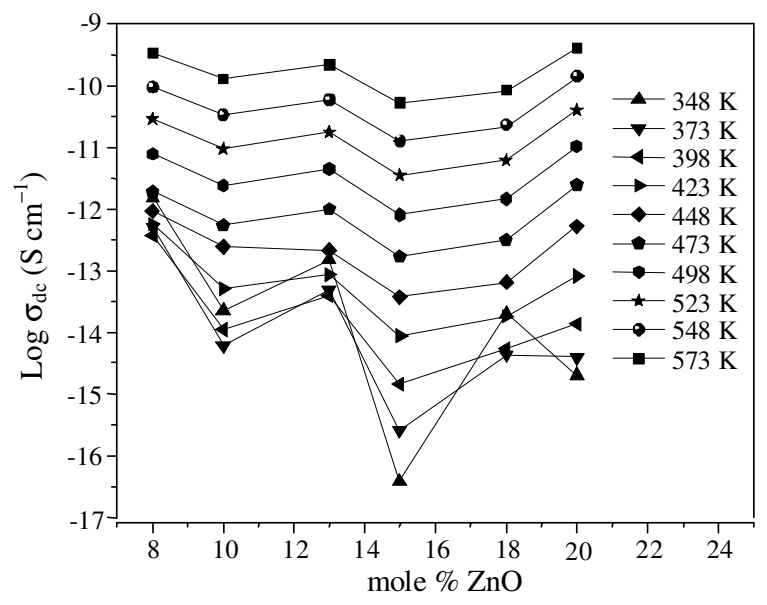

Fig. 3: Composition dependence of the dc conduction for $(\mathrm{ZnO})_{\mathrm{x}}(\mathrm{MgO})_{30}\left(\mathrm{P}_{2} \mathrm{O}_{5}\right)_{70-\mathrm{x}}$ glasses at different temperatures

Table 1: Variation of density $(\rho)$ and molar volume $\left(\mathrm{V}_{\mathrm{m}}\right)$ of $\mathrm{CM}$ series sample

\begin{tabular}{lll}
\hline & Density, & Molar volume, \\
Sample & $\rho\left(\mathrm{g} \mathrm{cm}^{-3}\right)$ & $\mathrm{V}_{\mathrm{m}}\left(\mathrm{cm}^{3} \mathrm{moL}^{-1}\right)$ \\
code & {$\left[ \pm 0.001 \mathrm{~g} \mathrm{~cm}^{-3}\right]$} & {$\left[ \pm 0.001 \mathrm{~cm}^{3} \mathrm{moL}^{-1}\right]$} \\
\hline CM 08 & 2.552 & 41.773 \\
CM 10 & 2.584 & 40.787 \\
CM 13 & 2.586 & 40.053 \\
CM 15 & 2.627 & 38.907 \\
CM 18 & 2.674 & 37.602 \\
CM 20 & 2.695 & 38.860 \\
\hline
\end{tabular}

The gradual increase of the $\mathrm{ZnO}$ concentration in relatively small contents is suggested to further depolymerize Bridging Oxygen (BO) bonds between adjacent $\mathrm{PO}_{4}$ tetrehedral and induces more $\mathrm{NBO}$ sites $^{[12]}$. Consequently, the average chain length of the phosphate network decreases and reduces the average interatomic spacing ${ }^{[11-13]}$. In other words, the compactness of the glass network has increased. It is well supported by the results as tabulated in Table 1 that show that the increases in density and decreases in molar volume as $\mathrm{ZnO}$ content increases. Meanwhile, such $\mathrm{Zn}^{2+}$ ions is more likely located in the interstitial position as network modifiers within the glass matrix rather than participating in the network in order to balance the net columbic charges of the structure ${ }^{[14]}$ and acting as blocking effect as well. Generally, with the highly disordered structures resulting in a broad distribution of both trap sites and migration barriers with the deepest traps likely controlling conduction ${ }^{[14]}$. Therefore, the relatively free mobile ions $\left(\mathrm{Mg}^{2+}\right)$ experience impeding effects along the conduction path and $\sigma_{\mathrm{dc}}$ decrease. 

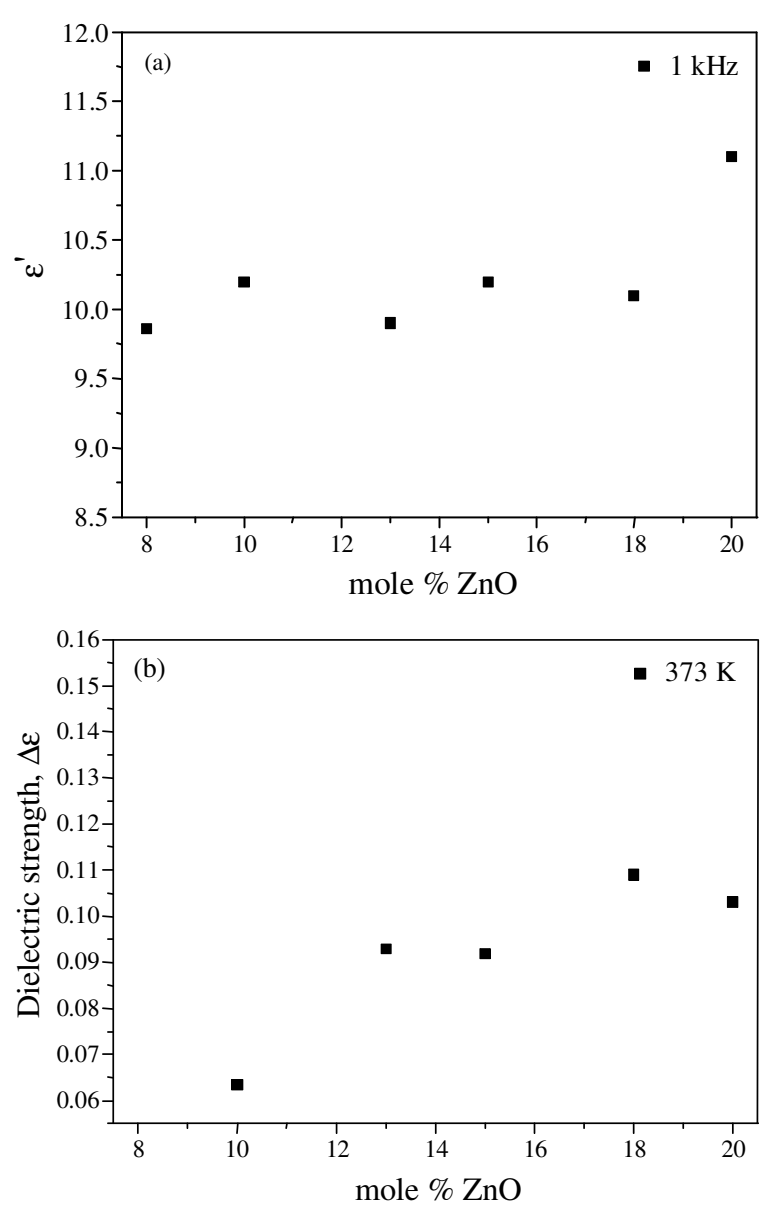

Fig. 4: (a): Composition dependence of the dielectric constant measured at $1 \mathrm{kHz}$ at temperature $473 \mathrm{~K}$. (b): The dielectric strength, $\Delta \varepsilon$, as a function of $\mathrm{ZnO}$ concentration for $(\mathrm{ZnO})_{\mathrm{x}}(\mathrm{MgO})_{30}\left(\mathrm{P}_{2} \mathrm{O}_{5}\right)_{70-\mathrm{x}}$ glasses at $373 \mathrm{~K}$

The reason for the increase in $\sigma_{\mathrm{dc}}$ is as follows. The phosphate glass with 20 mole $\% \mathrm{ZnO}$ possesses almost only the $\mathrm{Q}^{2}$ tetrahedral sites in the glass structure, i.e., converting the glass system from ultraphosphate to metaphosphate composition. Theoretically, the metaphosphate glasses $\left(50\right.$ mole $\left.\% \mathrm{P}_{2} \mathrm{O}_{5}\right)$ are composed primarily of phosphate chains with infinite long length and rings ${ }^{[13,15,16]}$. The depolymerization effects form the weaving continuous channels bifurcating through the phosphate network ${ }^{[14]}$ which served as conduction pathway. Moreover, the repulsive force onset along the channel among the NBO sites in sequence with the compactness of the glass structure leads in decreases of bottleneck size i.e., reducing the strain energy. Therefore, the diffusion movement of charge carriers is enhanced in the continuous conduction pathways and $\sigma_{\mathrm{dc}}$ increases.
Temperature is another contributing factor to $\sigma_{\mathrm{dc}}$ by means of a thermally-activated process. As thermal energy in the material is gradually enhanced, more and more charge carriers succeed in overcoming the binding energy i.e., attraction force among the glass network and able to diffuse in longer distances ${ }^{[17]}$. Consequently, the structure of glass becomes more disordered and increases the compactness of the glass network and dipole density increases.

Variations of $\varepsilon^{\prime}$ values with $\mathrm{ZnO}$ concentration are shown in Fig. 4a. As discussed above, $\mathrm{Zn}^{2+}$ ions are located in the interstitial position to preserve charge neutrality and the $\mathrm{Zn}^{2+} \cdots \cdot \mathrm{NBO}$ pairs represent dipoles. Therefore, the increasing trend is ascribed to the rise of dipolar density and hence increases the polarization. The variation in the dielectric strength, $\Delta \varepsilon$ as a function of $\mathrm{ZnO}$ concentration is shown in Fig. 4b. The dielectric strength values defined by $\Delta \varepsilon=\varepsilon_{\mathrm{s}}-\varepsilon_{\infty}$ were extracted from the fitting of the Havriliak-Negami equation. Dielectric strength represents the maximum polarizability that materials can withstand the applied electrical field without breaking down. Polarizability is greatest at those frequencies at which all dipoles can oscillate in response to the field ${ }^{[18]}$. Figure $4 \mathrm{~b}$ shows that $\Delta \varepsilon$ increases with increasing $\mathrm{ZnO}$ concentration indicating the amount of dipole density contributing to the polarization is raised. This results are expected and in line with the discussion above.

\section{CONCLUSION}

The dielectric permittivity of $(\mathrm{ZnO})_{\mathrm{x}}(\mathrm{MgO})_{30}\left(\mathrm{P}_{2} \mathrm{O}_{5}\right)_{70-\mathrm{x}}$ with different $\mathrm{ZnO}$ concentrations is frequency and temperature dependent. The variations in frequency and temperature are attributed to polarization and ion diffusion. From the thorough analysis of the experimental data, dc conduction loss dominates at lower frequencies and a small broad dipolar type relaxation occurs at high frequencies as observed in the dielectric loss factor plot. The dielectric data are analyzed in permittivity formalism by Havriliak-Negami model. Dielectric strength and dielectric permittivity results indicate that dipolar density is raised on account of $\mathrm{Zn}^{2+}$ ions which tend to localized at interstitial instead of substitution positions within the glassy $\backslash$ matrix. The dc conduction for the studied glasses was seen to depend on the changes in the network structure from ultraphosphate to metaphosphate compositions.

\section{ACKNOWLEDGEMENT}

The researchers gratefully acknowledge the financial support by the Malaysian government through 
the Ministry of Science, Technology and Innovation and Malaysian Academy of Sciences.

\section{REFERENCES}

1. Lanfredi, S., P.S. Saia, R. Lebullenger and A.C. Hernandes, 2002. Electric conductivity and relaxation in fluoride, fluorophosphate and phosphate glasses: Analysis by impedance spectroscopy. J. Solid State Ionics, 146: 329-339. DOI: 10.1016/S0167-2738(01)01030-X

2. Murali Krishna, G., N. Veeraiah, N. Venkatramaiah and R. Venkatesan, 2008. Induced crystallization and physical properties of $\mathrm{Li}_{2} \mathrm{O}-\mathrm{CaF}_{2}-\mathrm{P}_{2} \mathrm{O}_{5}: \mathrm{TiO}_{2}$ glass system Part II. Electrical, magnetic and optical properties. J. Alloys Compd., 450:477-485. DOI: 10.1016/j.jallcom.2006.11.005

3. Sahaya Baskaran, G., M.V. Ramana Reddy, D. Krishna Rao and N. Veeraiah, 2008. Dielectric properties of $\mathrm{PbO}-\mathrm{P}_{2} \mathrm{O}_{5}-\mathrm{As}_{2} \mathrm{O}_{3}$ glass system with $\mathrm{Ga}_{2} \mathrm{O}_{3}$ as additive. Solid State Commun., 145: 401-406. DOI: 10.1016/j.ssc.2007.11.008

4. Brow, R.K., D.R. Tallant, S.T. Myers and C.C. Phifer, 1995. The short-range structure of zinc polyphosphate glass. J. Non-Cryst. Solids, 191: 45-55. DOI: 10.1016/0022-3093(95)00289-8

5. Bano, N. and R.A. Hashmi, 1996. Electrical studies of leaves over wide frequency range. IEEE Trans. Dielectr. Elect. Insul., 3: 258-272. DOI: 10709878/96/

6. Saltas, V., F. Vallianatos, P. Soupios, J. P. Makris and D. Triantis, 2007. Dielectric and conductivity measurements as proxy method to monitor contamination in sandstone. J. Hazard. Mater., 142: 520-525. DOI: 10.1016/j.jhazmat.2006.08.051

7. Sankarappa, T., M. Prashant Kumar, G.B. Devidas, N. Nagaraja and R. Ramakrishnareddy, 2008. AC conductivity and dielectric studies in $\mathrm{V}_{2} \mathrm{O}_{5}-\mathrm{TeO}_{2}$ and $\mathrm{V}_{2} \mathrm{O}_{5}-\mathrm{CoO}-\mathrm{TeO}_{2}$ glasses. J. Mol. Struct., 889: 308-315. DOI: 10.1016/j.molstruc.2008.02.009

8. Kremer, F. and A. Schonhals, 2003. Broadband Dielectric Spectroscopy. Illustrated Edn., SpringerVerlag Berlin Heidelberg, ISBN: 3540434070, pp: 729.
9. Pye, L.P., H.J. Stevens and W.C. LaCourse, 1972. Introduction to Glass Science. Plenum Press, New York, pp: 722.

10. Shelby, J.E., 2005. Introduction to Glass Science and Technology. 2nd Edn., The Royal Society of Chemistry, USA., ISBN-10: 0854046399, pp: 291.

11. Higazy, A.A., 1995. Electrical conductivity and dielectric constant of magnesium phosphate glasses. J. Mater. Lett., 22: 289-296. DOI: 10.1016/0167-577X(94)-00254-1

12. Chaudhry, M.A. and Shakeel Bilal, 1995. Concentration-dependent electrical conductivity of phosphate glasses containing zinc oxide. J. Mater. Chem. Phys., 41: 299-301. DOI: 10.1016/02540584(95)01543-4

13. Liu, H.S., T.S. Chin and S.W. Yung, 1997. FTIR and XPS studies of low-melting $\mathrm{PbO}-\mathrm{ZnO}-\mathrm{P}_{2} \mathrm{O}_{5}$ glasses. J. Mater. Chem. Phys., 50: 1-10. DOI: 10.1016/S0254-0584(97)80175-7

14. Catlow, C.R.A., 1994. Defects and Disorder in Crystalline and Amorphous Solids (Nato Science Series Series C: Mathematical and Physical Sciences). 1st Edn., Kluwer Academic Publishers, Netherlands, ISBN-10: 0792326105, pp: 511.

15. Shih, P.Y., J.Y. Ding and S.Y. Lee, 2003. ${ }^{31} \mathrm{P}$ MAS-NMR and FTIR analyses on the structure of CuO-containing sodium poly- and meta-phosphate glasses. J. Mater. Chem. Phys., 80: 391-396. DOI: 10.1016/S0254-0584(03)00098-1

16. Marek Nocun, 2004. Structural studies of phosphate glasses with high ionic conductivity. J. Non-Cryst. Solids, 333: 90-94. DOI: 10.1016/j.jnoncrysol.2003.09.047

17. Rawson, H., 1980. Properties and Applications of Glass: Glass Science and Technology 3. Illustrated Edn., Elsevier Science Publishers BV., ISBN 13: 9780444423214, pp: 381.

18. Pollock, D.D., 1993. Physical Properties of Materials for Engineers. 2nd Edn., CRC Press, Inc., USA., ISBN-10: 0849342376, pp: 608. 